\title{
Sentido común, poder y libertad. Una lectura de Hobbes desde la filosofía de Arendt
}

Common Sense, Power and Freedom. Interpreting Hobbes from Arendt's Philosophy

Edgar Straehle Porras ${ }^{\star}$ Universidad de Barcelona (España)

Recibido: 2014-11-12

Enviado a pares: 2014-12-15

Aprobado por pares: 2015-08-14

Aprobado: 2015-08-30

Pensamiento y Cultura | ISSN: 0123-0999 | elSSN: 2027-5331

pensam.cult | Vol. 18-2 | Diciembre de 2015 | pp. 111-135

DOI: 10.5294/pecu.2015.18.2.6

\section{Para citar este artículo/To reference this article}

Porras, Edgar Straehle. 2015. "Sentido común, poder y libertad. Una lectura de Hobbes desde la filosofía de Arendt", Pensamiento y Cultura 18 (2): 111-135. DOI: 10.5294/pecu.2015.18.2.6 


\section{Sentido común, poder y libertad. Una lectura de Hobbes desde la filosofía de Arendt}

Resumen: en este artículo se estudiará la lectura crítica que Arendt hace del pensamiento de Hobbes. El objetivo consistirá en llevar a cabo un examen de la confrontación de sus concepciones antagónicas de lo que significa la política a partir de la comprensión diferente de términos clave como los de sentido común, libertad y poder. Este análisis muestra cómo el conflicto gravita en gran medida en torno a la reducción o no de esas categorías a la esfera subjetiva o privada.

Palabras clave: Hannah Arendt; Thomas Hobbes; sentido común; poder; libertad; autoridad.

\section{Common Sense, Power and Freedom. Interpreting Hobbes from Arendt's Philosophy}

Abstract: This paper studies Arendt's critical interpretation of Hobbes' philosophy. The goal is to examine the confrontation of its antagonistic conceptions of politics based on the different understanding of key terms such as common sense, freedom and power. This analysis shows how the conflict largely revolves around the reduction or not of those categories to the subjective or private sphere.

Key words: Hannah Arendt; Thomas Hobbes; common sense; power, freedom; authority. 


\section{Introducción}

Thomas Hobbes ha sido - sin duda alguna - uno de los grandes enfants terribles de la historia del pensamiento político. Esto a pesar de - o quizá precisamente a raíz de - la honda y no siempre reconocida influencia que tuvo sobre el pensamiento contemporáneo. Su huella ha sido enorme, aunque no haya sido muy bienvenida ni elogiada, por lo general. Y su obra ha sido objeto de una miríada de críticas e injurias, frente a las cuales tuvo que responder en vida, como aquellas que le dirigió el infatigable John Bramhall (obispo de Derby) debido a sus temerarios pronunciamientos acerca de la religión. Norberto Bobbio ha resumido esta cuestión en pocas palabras: "Hobbes tuvo muchos enemigos en su tiempo; por lo menos públicamente, sólo tuvo enemigos (...). Si se le nombraba era para discutirlo, refutarlo, rechazarlo, execrarlo" (Bobbio 1991, 296). No extraña por eso que, tras su deceso, los escritos del pensador británico fuesen calcinados por la Universidad de Oxford. Mientras tanto, según se cuenta, sus estudiantes lo celebraban alegre y divertidamente (Tönnies 1932, 90-91). El mito de Hobbes había comenzado.

$\mathrm{Su}$ (mala) fama sobrevivió a las cenizas de sus libros, a menudo al precio de aparecer como el contrincante por antonomasia o se dijera de él —como hizo Hegel- que no se podía encontrar nada filosófico en el conjunto de su obra. Por la incomodidad que despiertan sus afirmaciones, se le ha aplicado con frecuencia la denominada falacia del hombre de paja, y se ha tendido a hacer más lúgubre todavía su pesimismo antropológico con el objeto de forjar un cuadro más fácil de refutar o desestimar. Incluso se le ha reprochado en múltiples ocasiones ser un anticipador del totalitarismo, o ser él mismo un autor totalitario. Incluso, pese a que no deje de ser una apreciación en absoluto exenta de problemas, puede ser calificado como un heterodoxo precursor del liberalismo debido al margen de libertad que concede al fuero interno de las personas. Esto, sintomáticamente, fue visto por Carl Schmitt (1990) como un deplorable gesto de ingenuidad, ya que este resquicio habría sido la válvula de entrada por la que se habría colado el pensamiento liberal y que éste se habría encargado de engrandecer. 
Aquí es donde entra la ambivalencia del pensamiento de Hobbes, donde de manera extraña lo novedoso y lo moderno se engarzan con lo antiguo, y lo liberal con lo conservador. ${ }^{1}$ Como se sabe, también se ha subrayado que Hobbes inauguró una nueva manera de comprender la política. Leo Strauss, representante emblemático de esta posición, lo ha instalado como el fundador de la filosofía política entendida como tal (Strauss 2000, 236) y lo ha presentado "como el primer hombre que rompió radicalmente con la herencia premoderna, como el hombre que creó un nuevo tipo de doctrina social que sería el tipo moderno" (Strauss, 1970, 232-233). Por su parte, Arendt, pese a observar en determinado momento que este no era un pensador conservador (1996, 107-108), por lo general sostuvo una postura más matizada y ambigua, donde también lo nuevo se entremezcla con lo pretérito, donde la tentativa hobbesiana de romper con la tradición, y con la autoridad de los antepasados, no se acabaría de materializar del todo, sin negar por ello la novedad o las profundas repercusiones históricas de sus originales reflexiones filosóficas.

En este artículo se examinará la filosofía de Hobbes a partir de la lectura crítica de Hannah Arendt, y no solamente desde los escritos en los que lo cita explícitamente. A decir verdad, Hobbes ocupa un lugar extraño en el pensamiento de Arendt: por un lado, es preciso avanzar que no lo menciona con mucha frecuencia $y$, por otro, uno percibe su presencia en numerosos momentos en los que su nombre no es mencionado. No por casualidad Arendt llegó a decir que Hobbes había sido el único gran filósofo político (Arendt 2006, 176). Aunque en realidad la lectura arendtiana no solamente sirve para estudiar el pensamiento del británico desde otro enfoque, pues esta confrontación puede ser asimismo provechosa como una marca de contraste para examinar con mayor profundidad las aportaciones filosóficas de Hannah Arendt, lo que por desgracia ha sido poco tratado de manera específica y mucho menos exhaustiva en los

1 Esto se advierte por ejemplo en la conocida crítica de Bobbio, quien lo consideró como un precursor de las ideas liberales y señaló asimismo de él que "ideó una teoría del estado que debía agradar a los conservadores utilizando argumentos buenos para los liberales" (Bobbio 1991, 100). 
principales estudios sobre su pensamiento (una excepción parcial sería Forti, 2001).

En la primera de sus grandes obras, Los orígenes del totalitarismo, Arendt le dedicó un apartado a Hobbes, quien aparecía como el rostro por excelencia de la burguesía decimonónica (Arendt 2009, 293) y, por ende, del imperialismo. Aunque sea el lugar en el que Hobbes es analizado con mayor detalle, se trata de una lectura problemática y ad hoc que procura adaptar (y forzar) su pensamiento para hacerlo encajar con el diagnóstico que hace del imperialismo. En realidad, la misma Arendt no retomó más adelante las afirmaciones vertidas en este capítulo, las cuales fueron censuradas por varias personas de su entorno; entre ellas, el filósofo Eric Voegelin, quien en una carta que le mandó el 16 de marzo de 1951, calificó su interpretación de dudosa (zweifelhaft). ${ }^{2}$

Como hizo la misma Arendt, aquí preferimos dejar de lado esta interpretación temprana y centrarnos más bien en el rol que desempeña Hobbes en el desarrollo posterior de la filosofía arendtiana, especialmente en relación a la comprensión de la historia que ésta suministra. En otras palabras, en este artículo se tiene el propósito de reconstruir tentativa e hipotéticamente, a grandes rasgos, qué podría haber contenido el capítulo que habría dedicado a Hobbes en un proyecto de libro que apuntó en su Diario Filosófico y que finalmente no llegó a cristalizar (Arendt 2006, 468). El principal escollo reside en que, salvo un curso inédito que impartió acerca de Hobbes en la Universidad de Berkeley en 1955, no tenemos más que un cúmulo considerable de afirmaciones desperdigadas por sus abundantes escritos, las cuales tan solo sirven para confeccionar una imagen relativamente imprecisa de lo que tendría en mente.

\section{De la idea de política al sentido común:}

El pensamiento de Hobbes aparece en los textos de Hannah Arendt como un posicionamiento teórico antitético al que la autora alemana

2 Más adelante, un pensador como Hauke Brunkhorst (2006: 92) no ha tenido reparos en considerarla como insostenible. 
propugna en sus obras así como el máximo representante de la filosofía política moderna (Arendt 1993, 326). Aunque esa modernidad no deja de estar íntimamente asociada a una tradición de la filosofía que ella remonta hasta la obra de Platón, desde donde se había comenzado a pensar la política desde los patrones de la vida contemplativa. Por eso, la lectura crítica que la autora alemana aporta de Hobbes debe ser leída a la luz de una serie de desplazamientos efectuados previamente por el pensador ateniense.

Para Arendt, el pensamiento político de Platón, guiado por modelos como los proveídos por la geometría y consagrado a garantizar el mantenimiento del armónico orden deseado, se caracteriza por el intento de domesticar la acción política y de subordinarla férreamente a las metas estipuladas desde la filosofía (véase sobre todo Arendt, 1997). Hobbes se distancia de esta concepción platónica cuando devalúa la importancia del bios theoretikós y restaura la primacía de la filosofía práctica, pero lo hace al precio de reproducir de nuevo la disociación que Platón había trazado con anterioridad entre pensamiento y acción, entre teoría y praxis. Hobbes no logra escapar a una tradición de la filosofía política que, en opinión de Arendt, traiciona la idea misma de lo que sería lo propio de la política. A su juicio, el filósofo inglés cae en esta tradición a la hora de perpetuar a su manera y con numerosas variaciones dignas de ser mencionadas a continuación esta misma tradición. Por decirlo de una manera no exenta de polémica, en cierto modo Hobbes seguiría siendo un autor platónico.

La traición platónica de la filosofía a la política se había originado en el convencimiento de que el filósofo se tenía que situar fuera de la polis para hablar de ella y decidir lo que ésta debe hacer. En este sentido, la explicación que ofrece Arendt del mito de la caverna resulta ejemplar: ahí se ilustra que aquella persona que debe guiar a la comunidad política es precisamente la que no ha tenido la capacidad o la voluntad de adaptarse a ella, quien encuentra la verdad fuera de la sociedad y quien, a la postre, deviene su víctima (Arendt 1997, 51ss). ${ }^{3}$ De ahí que la filosofía

3 La afirmación de que el filósofo debe ser el gobernante de la polis ya causó una honda sorpresa en Glaucón, el interlocutor de Sócrates en La República, quien en el citado diálogo 
política de Platón aparezca como la imposición de un modelo exterior urdido desde la razón.

De una manera análoga, a pesar de la devaluación o del menosprecio de la vida contemplativa que efectúa, el pensamiento de Hobbes no deriva en absoluto en una restauración de la acción, al menos en el sentido arendtiano. Como en Platón, también encontramos en la filosofía del pensador británico la reivindicación de una acción desnaturalizada, mutilada, simplificada, cuyo propósito no es más que la simple y a la vez perfecta ejecución de un plan forjado de antemano (siempre que se deje espacio a una libertad negativa que a nivel político es inocua y no estorba). Se pasaría a ver la praxis, que en el pensamiento aristotélico se identificaba con la actividad política, como si fuera una forma más de fabricación o poiesis, por lo que comparece como una cuestión técnica de medios-fines que estaría en manos de la persona que detenta el poder y que despoja a la acción de ese potencial inaugural, de esa capacidad de innovación o ruptura que la pensadora alemana le asigna y que, al fin y al cabo, pone en perenne riesgo la persistencia del statu quo. El resultado de semejante planteamiento político es el surgimiento del Leviatán en tanto que encarnación modélica de esta forma de comprender la política a partir de la lógica instrumental de la fabricación.

Tanto en Hobbes como en Platón se propugna una política ajena a la pluralidad. Se la identifica más bien con una suerte de episteme que toma a la geometría como modelo privilegiado a partir del cual se piensa y afronta la política. ${ }^{4}$ Hobbes creyó ciertamente haber establecido los fundamentos sólidos de una nueva ciencia, tal y como él mismo se

expresa lo siguiente: “iQué palabras, Sócrates, qué discurso has dejado escapar! Después de hablar así, tienes que pensar que se han de echar sobre ti muchos hombres nada insignificantes, se quitaran sus mantos, por así decirlo, y, despojados de estos, cogerán la primera arma que tengan a mano, dispuestos a hacer cualquier barbaridad; de modo que, si no te defiendes con tu argumento o esquivas los golpes, verdaderamente expiaras tu falta convirtiéndote en objeto de burla" (Platón 1986, 283).

4 A pesar de que Hobbes se posicione en contra de la tradición política clásica, es preciso remarcar que entre Platón y Hobbes hay notables afinidades, entre las cuales se debe incluir la frase que Clinias en Las leyes pone en boca del legislador de los cretenses: "lo que la mayoría de los hombres llama paz lo es solo de nombre. En realidad hay siempre por naturaleza una guerra no declarada de todas las ciudades contra todas" (Platón 1987, 191). 
encargó de proclamar explícitamente en su De Corpore (Hobbes 2000, 30). En este texto expuso con orgullo que la filosofía civil, entendida ésta en un sentido científico, no era más antigua que su libro De Cive.

El problema radica en que esta vocación científica no se cumplió ni mucho menos de una manera tan estricta o rigurosa. Hobbes escribió en la introducción al Leviatán que "la sabiduría se adquiere no ya leyendo en los libros sino en los hombres" (Hobbes 1980, 4) y acto seguido, en un giro introspectivo semejante al empleado por Descartes, ${ }^{5}$ puntualizó que a causa de la similitud de las pasiones humanas valoraba el clásico "conócete a ti mismo" (el gnothi seautón délfico) como una adecuada vara de medir el conocimiento de los hombres en general. Si bien reconocía que los deseos y aversiones de cada ser humano son distintos, añadió que la propia mecánica del deseo era idéntica entre ellos, razón por la que no era necesario observar a los demás. En su opinión, una inspección introspectiva bastaba para elucidar los rasgos esenciales de la naturaleza humana y añadió además que "quien ha de gobernar una nación entera debe leer, en sí mismo, no a este o aquel hombre, sino a la humanidad" (Hobbes 1980, 5).

Así pues, la ciencia es problemáticamente asociada a la introspección, aunque esto contrasta con otras afirmaciones suyas. Por ejemplo, cuando en el prefacio al De Cive asegura poner en primer lugar

como principio universalmente conocido por experiencia y no negado por nadie, que la condición de los hombres es tal, por naturaleza, que si no existe el miedo a un poder común que los reprima, desconfiarán los unos de los otros y se temerán mutuamente, y que al ver que todos pueden protegerse con sus propias fuerzas con derecho, entonces necesariamente lo harán (Hobbes 1999, 7-8).

En este fragmento, así como en otros semejantes, Hobbes habla de un principio universalmente conocido por experiencia (si esto es posible) y

5 Otro punto en común es la importancia de un fundamentismo de raigambre cartesiana en Hobbes, quien destacó que el De Cive era la consecuencia del De corpore y del De homine. Lo curioso es que el primer libro se publicó en 1642 mientras que los otros dos lo fueron en 1655 y 1658 respectivamente. 
no negado por nadie, el cual obviamente no era cierto. Lo que aquí nos interesa es lo primero, puesto que el empirismo político de Hobbes resulta más problemático cuando él mismo, después de exponer el bellum omnium contra omnes de su celebérrimo estado de naturaleza, no tiene problemas en poner en tela de juicio la existencia de una guerra semejante en la historia y confiesa incluso que cree que nunca haya ocurrido efectivamente así (Hobbes 1980, 103), lo que de todos modos no parece incidir en absoluto en el contenido o en el tono de sus reflexiones.

Por consiguiente, es difícil asumir como científicas las afirmaciones que Hobbes profirió acerca de la naturaleza humana y, como se ha repetido en distintas ocasiones (por ejemplo MacPherson 2005), uno se siente inclinado a pensar en que cuando hablaba del estado de naturaleza, Hobbes estaba más bien delineando y proyectando de manera regresiva un retrato personal de la coyuntura histórica en la que le tocó vivir, influenciado en buena medida por el desasosegante espectro de la guerra civil, contra cuyo monstruo (el Behemoth) planteó la necesidad del Leviatán. Así se explicaría que, precisamente en un periodo que coincide con la génesis del capitalismo, la primera de las causas de discordia en el estado de naturaleza fuera justamente la competencia, que describió como la lucha en busca de la obtención de un beneficio (Hobbes 1980, 102).

En resumen, este recurso hobbesiano a la ciencia, plasmado en el empleo sistemático y explícito del método analítico-sintético de Galileo, sería de por sí problemático, y además — según Arendttendría la consecuencia de hacerle volver la espalda a los contenidos de la realidad externa (Arendt 1993, 325s). Así se plasmaría el error de un racionalismo que, a pesar de presentarse como una forma de realismo político, se encierra en sus prejuicios y no atiende al auténtico rostro de la realidad, que es incapaz de captar la pluralidad y la diversidad de ésta. Paradójicamente, el cientifismo de Hobbes es lo que conduciría a la ruptura con el mundo real. Sus efectos no solamente serían de carácter teórico, pues esta concepción habría contribuido a romper los lazos con el prójimo y a concebir la política desde una subjetividad escindida de los demás.

Todo esto habría coadyuvado en la disolución de lo que entonces se entendía por «sentido común» o common sense. Según Arendt, 
en este proceso de interiorización, el sentido común es arrancado del mundo y deja de estar enraizado en la realidad compartida, perdiendo su carácter de sensus communis (o sentido de la comunidad); deja de ser una forma de conocimiento intersubjetivo y "se hace independiente de lo dado como experimentable en el plano sensible y se transforma en una lógica, en un cálculo de consecuencias, que destruye todo lo real" (Arendt 2006, 455). Así pues, de ser un aprendizaje realizado en compañía de los demás o ser un sentido como los otros (Arendt, 2003: 130) pasa a ser una facultad racional que supuestamente cada uno atesora de forma individual, dentro de sí. De este modo se convierte en una especie de sentido o facultad interna que funciona de manera equivalente en el resto de personas racionales y que, además, es asimilado a una suerte de razonamiento matemático como saber el resultado de una operación elemental como dos más dos (Arendt 1993, 302; Arendt 2002, 70-78). El sentido común deviene en una facultad que tan solo está hipotéticamente compartida con la de los demás, y que al no nutrirse de la experiencia de los demás, deja de ser intersubjetiva, desestimando de este modo las diferencias de cada uno y desatendiendo a la complejidad de lo real. En su enfrentamiento a la tradición, la cual se encuentra asociada el sentido común (Arendt, 2008: 79), se pierde de paso su contacto con el mundo. Recuérdese que Arendt entiende por la palabra "mundo" no solamente el lugar físico en el que habitamos sino el espacio común - forzosamente plural- que construimos y preservamos fundamentalmente por medio de acciones (de encuentros y desencuentros); también de objetos, los cuales le aportan su imagen de solidez y durabilidad.

La importancia del sentido común se evidencia cuando Arendt comenta que "el sensus communis es el sentido propiamente humano porque la comunicación, es decir, el discurso, depende de él" (2003, 130). La pérdida de este sentido común está acompañada de la pérdida de un espacio común o intermedio, aquel que sería en su sentido propio el espacio de la política. Como ha apuntado Anne-Marie Roviello, "el sentido común es el acuerdo, o más bien a lo que apunta (visée) un acuerdo en el marco de la diversidad de los puntos de vista" (1987, 
139). Por eso mismo aparece como el horizonte indeterminado de una comunidad de sentido, donde paradójicamente el sentido común es el sentido de la irreductibilidad de los diferentes puntos de vista sin los cuales la comunicación o la política quedan desprovistas de su razón de ser, puesto que el fundamento mismo del mundo sería la pluralidad.

Además, el sentido común no se enfrenta en su extremo tan solo al solipsismo sino también al indiferentismo. La permanencia del mundo requiere del compromiso y de la actuación de sus participantes, los cuales deben esforzarse en salir de su interioridad para expresar y articular su punto de vista. En conexión con esto, Roviello añade más adelante que Arendt define el sentido común como "la facultad que nos permite inserirnos y orientarnos en el mundo, de hacer de éste una morada (demeure)" (1987, 148). La falta de sentido común nos condena a la desoladora experiencia de la falta o pérdida de mundo (Weltlosigkeit o Worldlessness) que Arendt califica explícitamente como una forma de barbarie (Arendt, 2001, 23). ${ }^{6}$

En pocas palabras, para la autora alemana el sentido común es un sentido inherentemente asociado a la política. Como ocurre con Hobbes, su despolitización (a la vez que desmundanización) coincide, no por casualidad, con la emergencia de un tipo de antropología filosófica en la que el hombre, lejos de ser presentado como un zoon politikón, puede pasar a ser aprehendido al margen de los demás, de manera independiente y aislada, desgajado de ellos. Con ello desaparece el rol fundamental que Arendt asigna al espacio intermedio como el espacio propio de la política. De ahí que el mismo Leviatán aparezca por necesidad como el constructo que se erige desde la lógica de la fabricación, que se diseña y realiza en la soledad, en el apartamiento del mundo; como un constructo que procede de este sentido común privatizado o sensus privatus. La pérdida de confianza en el contenido de los sense data se extiende a la pérdida de confianza en los demás y en la tradición, así como se plasma en la poca halagüeña concepción del estado de naturaleza: en dicho estado no estaríamos al margen de los otros hombres en realidad, sino frente a o directamente en contra de ellos.

6 En relación con esto, téngase en cuenta la siguiente frase de Hannah Arendt: "Sólo puede haber hombres en el sentido auténtico del término donde hay mundo y sólo hay mundo en el sentido auténtico del término donde la pluralidad del género humano es algo más que la multiplicación de ejemplares de una especie" (1997b, 118). 


\section{En torno al poder y a la libertad}

No es necesario recordar el celebérrimo retrato que Hobbes confecciona del estado de naturaleza, y cómo esto conduce a la necesidad del Leviatán. Lo que aquí nos interesa es que el siniestro panorama que plantea se traduce con toda coherencia en una filosofía política que, en aras de preservar la vida de los futuros súbditos, se vertebra sobre la idea de poder; de un poder como el poder que detenta o impone un sujeto sobre los demás (y no un poder relacional como el arendtiano). Además, esta concepción del poder aglutina problemáticamente en su seno otros conceptos cercanos pero no del todo equivalentes, tales como la potentia, la potestas e incluso la auctoritas, lo que ha tenido unas consecuencias muy importantes para la semántica histórica de este último término.

El concepto de auctoritas (o authoritas, como lo escribe Hobbes) ha sufrido numerosas transformaciones a lo largo de la historia, y hasta ese momento se había apreciado como un concepto complementario pero en ningún caso reducido al concepto de poder (véase Domingo 1999; Preterossi 2003). Hobbes rompe con la idea tradicional de auctoritas, y para Arendt (1996) esta fractura es todavía más chocante dado que en su opinión la autoridad descansa por definición en el otro, en la persona que obedece a quien ostenta la autoridad a raíz de una suerte de reconocimiento, confianza o prestigio. En este sentido, la autoridad se revela como incompatible con la coerción, el chantaje o la violencia, así como compatible con la conservación de la libertad. La autoridad, por decirlo brevemente, es una concesión otorgada desde fuera y que nadie se puede arrogar o apropiar a priori. O que no se puede forzar. Por la misma razón, la autoridad - en la medida en que un poder carece de autoridadaparece como aquello que puede fragilizar y desautorizar al poder, como aquello que revela su arbitrariedad y su injusticia. Un poder sin autoridad es aquel que no tiene por qué ser seguido u obedecido.

En Hobbes, en cambio, el poder pasa a monopolizar e instrumentalizar la autoridad, por lo que desprovee a ésta de su significado original. Esta subordinación de la autoridad con respecto al poder se plasma por ejemplo en la defensa de una postura como el erastianismo (donde la 
religión se somete a los intereses de la política) o en su célebre sentencia authoritas, non veritas, facit legem. ${ }^{7}$ También se sirve de la palabra dominium (reservaba al derecho o la posesión de las cosas) que, en su filosofía, hace del gobernante una suerte de propietario o dueño privado de la civitas (Zarka 1997, 189). Por último, el poder pasa a ser identificado bajo su rostro más propio y absoluto con la idea de soberanía, concepto que había sido desarrollado el siglo anterior por Jean Bodin (1997), una de las principales influencias en su pensamiento.

El poder soberano —además de único, absoluto e indivisibleaparece para Hobbes como indisputable: como el patrimonio exclusivo e indiscutible de uno solo. Por eso el pensador británico dejó claro que el Estado retenía el derecho de guerra contra el discrepante (Hobbes 1999, 57). De ahí que un gobierno de esta clase que — de acuerdo con su opinión- era el resultado de la ciencia política, choque curiosa o paradójicamente contra la misma ciencia o la filosofía. Y que, por ejemplo, en el conocido capítulo 46 del Leviatán, abogase por la subordinación de la filosofía al poder y a castigarla en el caso de que infringiese las leyes, incluso cuando tuviera razón. Asimismo enfatizó que se debía prohibir la amplia libertad de las universidades, a las que describió como un caballo de Troya en el gobierno y desde donde consideraba que en cierta medida se había incubado la guerra civil inglesa (Hobbes $2013,55)$. Junto a esto, también la idea de libertad tuvo que padecer una transformación (o una merma) radical en su pensamiento, para llegar a ser una libertad básicamente apolítica, una libertad no pública.

Por el contrario, Arendt piensa que "la libertad como hecho demostrable y la política coinciden y se relacionan entre sí como las dos caras de una misma moneda" (Arendt 1996, 161). Ella denunció la reducción de la idea de libertad a un fenómeno psicológico o de la voluntad, lo que conducía a su expulsión de la política, o a jugar un rol marginal. Bajo

$7 \quad$ Y eso enlaza además con la comprensión hobbesiana de ley, donde ésta es tildada de justa simple y exclusivamente por el hecho de proceder del Estado y no por los contenidos que pueda tener (véase Hobbes 1980, 104; 1999, 285). Dicho en otros términos, propugna un concepto de ley que se despreocupa por gozar de autoridad entre los súbditos y que consuma - lo que Paolo Grossi (2003) ha denominado- la emergencia de la mitología jurídica de la modernidad. 
esta comprensión, la libertad era equiparada finalmente a la soberanía, a la que en su opinión se contraponía. Así la libertad de uno aparecería como incompatible o en conflicto con la de los otros, como lo que no permite la existencia de la pluralidad. Para Arendt, donde hay soberanía, hay dominio, imposición, superioridad, autosuficiencia, arbitrariedad y, al fin y al cabo, violencia (Arendt 1993, 254; 1996, 177) o tiranía (Arendt 1988, 207s). Por lo mismo, en su seno no hay esfera pública, acción o espontaneidad. Arendt consideró que la soberanía, así como la noción de voluntad sobre la que se sostiene, era intrínsecamente antipolítica; una forma política de despolitizar la política, y sentenció que "si los hombres quieren ser libres, deben renunciar precisamente a la soberanía" (1996, 177). En el Diario Filosófico puso énfasis asimismo en el estrecho vínculo existente entre la soberanía y el ideal político de la fabricación, el cual conduce sin remisión a la erradicación (Ausrottung) de la libertad (Arendt 2006: 82).

La pensadora alemana tematizó una concepción eminentemente política de la libertad que no se sitúa en la interioridad del individuo sino en el afuera, enraizada en un lugar o espacio intermedio, con los otros y no frente a ellos. Así pues, la libertad es identificada con la participación en los asuntos públicos o en la admisión en la esfera pública (Arendt 1988, 41); más aún, no es caracterizada como el fin de la política sino como su sentido (Sinn). Para Arendt, por definición, no podría haber política propiamente hablando sin libertad (Arendt 1997b, 61-62 y 79). Y una de las principales consecuencias de esta libertad, entendida en buena medida en tanto que espontaneidad, radica en la capacidad de poder comenzar o desatar cosas nuevas e imprevistas (cfr. Arendt 1996, 182; Arendt 1997b, 66; Arendt 2006, 351).

Desde luego, en el pensamiento de Hobbes, hallamos una interpretación diametralmente opuesta, donde la libertad pasa a ser definida como algo semejante a lo que Isaiah Berlin denominó una libertad negativa. Puede ser motivo de sorpresa que la concepción de libertad de Hobbes sea entendida como una ausencia de impedimentos externos que menoscaban o imposibilitan el movimiento de alguien (Hobbes 1980, 106; 1999, 85). En primer lugar, porque se postula una libertad que a fin de cuentas no es autosubsistente sino que existe de manera mediata o indirecta, en virtud 
de la gracia o del criterio del soberano, ya que el margen de maniobra que se le asigna a uno es el que viene demarcado por el silencio de la ley. Según esta interpretación un ciudadano sería libre, no por sí mismo sino, por lo que otro, por aquel sobre quien recae el poder dictamine. Por eso mismo Hobbes puede hacer extensiva esta idea de libertad sobre las criaturas irracionales e incluso sobre las inanimadas (Hobbes 1980, 171) o proponer que el agua aparezca como su imagen paradigmática. Se pone de manifiesto entonces (coherentemente con su versión mecanicista del mundo) que lo relevante ya no es el motor de la acción, esto es, que sea uno mismo quien decida lo que va a hacer o autodeterminarse, sino que ninguna instancia externa obstaculice las propensiones de cada uno. Al conceptualizar la libertad desde una metáfora relativa al movimiento, se la inscribe en una dimensión espacial en la que tiene mucho sentido que se la visualice en tanto que una esfera o un refugio donde uno se parapeta o no queda obstaculizado por la intromisión de impedimentos externos. En realidad, más que un espacio libre se revela como un espacio liberado de las interferencias o de las injerencias que pudieran provenir de fuera, por lo que este espacio es visto como el terreno de lo que posteriormente se denominará privacidad (privacy).

La libertad en Hobbes ya no tiene que ver con el vivere libero de la tradición republicana que se materializaba en una acción consagrada al cultivo y mejora de la comunidad (véanse por ejemplo Skinner 1998 y Pocock 2002). Esta versión de la libertad era considerada por el pensador británico como una actitud próxima a la vanagloria, mientras que la propia se descubre antes bien como una apartamiento del mundo que halla su más polémica y radical ejemplificación en la figura del idiotes griego. De este modo, la libertad es la capacidad de autodeterminarse a nivel individual (como se ha comentado más arriba), pero, al mismo tiempo, también es algo que corta con la posibilidad de autodeterminarse de manera colectiva o política. La comprensión hobbesiana de la libertad, desplazada a la esfera privada, hace de ella un elemento inocuo e intrascendente a nivel político, y permite que su existencia sea conciliable con la defensa de una idea de poder tan fuerte. En un pasaje memorable, Hobbes equiparó el grado de libertad de la ciudad de Lucca con el de Constantinopla, en aquel entonces símbolo por excelencia del despotismo (Hobbes 1980, 175). 
Por otro lado, en una de las variaciones más significativas de la evolución del pensamiento de Hobbes, el contrato político pasa de ser descrito como acto de renuncia, en su tratado De Cive, a ser expuesto como una autorización en el Leviatán (véase Skinner 2010; Zarka 1997, 69 ss); en este sentido, el contrato no se traduce en la conquista de algún poder o derecho. Este sagaz movimiento es fundamental puesto que así los súbditos asumirían - en teoría - un rol activo y no meramente pasivo, convirtiéndose de este modo en corresponsables de los actos del soberano. A raíz de esta autorización, al Leviatán se le atribuye un respaldo popular que inmoviliza y deslegitima la discrepancia y, sobre todo, la rebelión. En términos hobbesianos, los súbditos no serían los actores de la acción - papel reservado al que detenta el poder- sino los autores de ella en tanto que personas firmantes del contrato; razón por la que no sería legítimo que pudiesen acusar al soberano de cometer actos de injusticia, ni mucho menos sublevarse. En tal caso se estarían incriminando a sí mismos al haber sido ellos los que autorizaron su llegada al poder (Hobbes 1980, 144). Así pues, la autorización se destapa en definitiva como una forma de incrementar la sujeción.

En este punto nos tropezamos con uno de los aspectos clave que atraviesa la discusión entre Hobbes y Arendt. En ambos la idea de poder se encuentra en el epicentro de su filosofía, aunque parten de una significación harto distinta. En sentido estricto, el poder en Hobbes tan solo puede ser de un sujeto, toda vez que cualquier atisbo de división o compartición implica necesariamente su puesta en duda y disolución. De ahí que critique con dureza a los autores clásicos que, como Cicerón o el Maquiavelo de los Discorsi, se posicionan a favor de una constitución mixta, pero que, en opinión de Hobbes, implica necesariamente el estallido de la guerra civil o la anarquía; o que, con el pacto como autorización, permite que el poder se muestre no solamente como una voluntad política única sino también pública, nombrada como la voluntad de todos (Zarka 1997, 305; Zarka 2008, 113ss).

Aunque la posición de Arendt es diametralmente contraria a la de Hobbes, ella reconoce en él al más grande filósofo político, solamente por el hecho de haber descubierto que el poder ocupa el lugar cardinal de la política. En ¿Qué es la política?, ella escribe una frase que se puede 
entender como una expresión de reconocimiento: "La política surge en el entre y se establece como relación (Bezug). Así lo entendió Hobbes" (Arendt 1997b, 46). Este final puede llevar sin embargo a un malentendido, y a inferir que Hobbes, según la interpretación de Arendt, valoró el entre como el locus propio de la política. Este equívoco se puede detectar y enmendar con facilidad si uno consulta el Diario filosófico, donde Arendt $(2006,17)$ repite exactamente la misma oración y añade otras que sirven para contextualizar y profundizar en esta cuestión. ${ }^{8}$

La citada frase se halla dentro de una extensa anotación del diario donde señala que existen dos razones que pueden impedir que la filosofía encuentre el lugar de la política. Primero, tomar al hombre como zoon politikon, cuando en realidad sería propiamente apolítico, dado que lo político se encontraría en realidad fuera de nosotros, en el espacio intermedio o entre (Zwischen o en otros fragmentos Zwischenraum). Por lo tanto, Arendt critica una versión aristotélica de la política, pues incurre en una comprensión subjetiva de la misma, al enfocarla desde el punto de vista de los hombres y ponerla como un rasgo ínsito a su naturaleza (Arendt 2006, 25). Este error habría sido evitado gracias a las reflexiones de autores como Maquiavelo y Hobbes, quienes centraron el ámbito de la política en la cuestión del poder y, por lo tanto, contribuyeron a su progresiva autonomización. En opinión de Arendt, la grandeza de Hobbes habría consistido en darse cuenta de que el poder es el eje en torno al cual gira el pensamiento político, y que su obstáculo no se halla en la naturaleza sino en los otros hombres, no en la materia sino en la espontaneidad imprevisible de los otros. En el fondo, Hobbes se percató de que el problema central de la filosofía política residía en la cuestión relativa a la pluralidad (Arendt 2006, 81).

Así pues, el pensador de Malmesbury habría acertado a la hora de discernir cuál era el problema de la política, pero no a la hora de responderlo; pues encapsuló el concepto maquiavélico de poder en el sujeto, con lo que en cierto modo se recaería en la interpretación aristotélica. Si antes el problema yacía en que lo político era el sujeto, ahora reside en

8 El error del artículo de Claudia Fuentes (2009), por otro lado de muy recomendable lectura, ha sido no tener en cuenta el Diario filosófico de Hannah Arendt a la hora de leer este pasaje. 
que el poder se encuentra en el sujeto, dentro de él. De ahí esa frase "así lo entendió Hobbes" de la versión en castellano, que en realidad traduce imperfectamente el original "dies hat Hobbes verstanden" (Arendt 1993, 11). Estas palabras quieren decir más bien "esto lo comprendió Hobbes" e implica, como se comprueba en la anotación del Diario filosófico, que hubo algo que en verdad no acertó a comprender adecuadamente.

La cuestión que Hobbes no habría entendido enlaza con la otra razón que nos impediría encontrar el lugar propio de la política. Ésta es, en palabras de Arendt, la concepción monoteísta, la idea de un Dios a cuya imagen fue creado el hombre y que, consiguientemente, lleva a pensar la pluralidad desde la perspectiva del hombre en singular y, por lo tanto, a disolverla o hacerla desaparecer. Si tenemos en cuenta todas las acusaciones que recibió en vida, Hobbes habría pensado el hombre paradójicamente, desde la soledad de Dios (Arendt 2006, 17), la cual le impediría asomarse a captar y valorar la heterogeneidad de lo real, que fundiría la pluralidad de los hombres en un individuo humano reducido a una abstracción -en verdad, monstruoso e inhumano- que, al final, pasaría a llamarse humanidad (Arendt 2006, 21), y que, en este caso, desembocaría en la guerra de todos contra todos.

De ahí también que la historia del estado de naturaleza, aun tratándose de una historia imaginada o ficcionada, pase a ocupar el lugar propio de la política, dado que esta surge de una suerte de mito prepolítico de la política que culmina en la expulsión de lo genuinamente político. La libertad y la igualdad se manifiestan en un estado natural, también calificado de bestial, ${ }^{9}$ cuyo telos es confirmar que su desaparición es una condición indispensable para todo proyecto político viable. El momento precontractual, asumido como historia, como una historia además ineluctable o irreversible, conduciría a una legitimación de la supresión de lo propia-

9 Aquí no disponemos de espacio para debatir en detalle los problemas que arrastra su debatida concepción del llamado estado de naturaleza, preñado desde el principio de una cierta teleología que recuerda a la causa final de los escolásticos, que puede desprenderse de frases como la siguiente: "Fuera del Estado está el reino de las pasiones, la guerra, el miedo, la pobreza, la fealdad, la soledad, la barbarie, la ignorancia, la crueldad; en el Estado el reino de la razón, la paz, la seguridad, la riqueza, la belleza, la compañía, la elegancia, la ciencia, la benevolencia" (Hobbes 1999, 90). 
mente político y a que un soberano (quien bajo la imponente apariencia del Estado se muestra literalmente como deus ex machina) se arrogase el monopolio de la política. Así se efectúa la subjetivización de la idea de poder, encarnado en la persona artificial del Estado, lo que colisiona frontalmente con la particular idea de poder aportada por Hannah Arendt.

El poder en Hobbes, a pesar de que lo denomine común en varias ocasiones, es el de la imposición de la voluntad de uno sobre la de los demás, de modo que el poder de otro entra en competencia o en pugna con él y va en detrimento del suyo. En cambio, en Arendt el poder "nunca es propiedad de un individuo; pertenece a un grupo y sigue existiendo mientras que el grupo se mantenga unido" (Arendt 2005, 60). Según la interpretación arendtiana, el poder de un bando o de una persona ya no se enfrenta o contrarresta al de otro sino que lo legitima, lo apuntala y lo refuerza. A fin de cuentas, el reconocimiento resulta necesario para que el poder sea digno de tal nombre. De ahí que remita a (o se materialice en) una acción en concierto con los demás, así como en la existencia de un espacio intermedio donde se pueda desplegar esta acción, y donde el acontecimiento de la pluralidad pueda hacer acto de presencia. Un espacio que obviamente en el planteamiento de Hobbes no tiene lugar.

Así como con la cuestión del sentido común y con la de libertad, el problema de la idea hobbesiana de poder gravita en que Arendt no acepta (y además juzga como extremadamente perjudicial) la reducción de este a una concepción por la que aparece recluido en la esfera de la subjetividad, lo que es difícilmente compatible con su interpretación de la política. Arendt trata de desubjetivizar estos conceptos políticos y emplazarlos en el espacio intermedio, de manera que libertad y poder (y en parte también el sentido común) terminen por ser interdependientes e incluso coextensivos. Según Arendt, la separación de sendos términos en los albores de la Modernidad habría tenido unos efectos negativos en la teoría política, como ella resume con la siguiente frase (la cual obviamente puede ser leída en contraposición al pensamiento de Hobbes y que describe un rasgo de la situación del presente):

"La libertad ha cambiado de lugar; ya no reside en la esfera pública, sino en la vida privada de los ciudadanos, que deben ser defendidos frente al poder público. Libertad y poder se han separado, con lo cual ha 
comenzado a tener sentido la funesta ecuación de poder y violencia, de política y gobierno, y de gobierno y mal necesario" (Arendt 1988, 183).

Según Arendt, el poder es inapropiable por parte de un individuo, ni siquiera por parte del soberano. En tanto que se muestra en la acción, el poder se caracteriza necesariamente por su espontaneidad, por su ruptura o su desbordamiento, por la capacidad de iniciar cosas nuevas y de desatar acontecimientos. El espacio donde brota el poder, por eso, es el entre de la pluralidad (Arendt 2006, 154), de modo que su apropiación por parte de un individuo no sería más que un contrasentido que conlleva ipso facto la evaporación del poder. En realidad, el poder para ella solamente puede ser potencial por definición (Arendt 1993, 223) y todo gesto de apropiación debe ser entendido como un acto de violencia que despoja al poder de su ser. La violencia es capaz de destruirlo (o de expropiarlo) pero no de generarlo. Y la manera de aniquilar el poder, como habría realizado el pensamiento de Hobbes a nivel teórico, sería rompiendo el grupo y convirtiéndolo en una suma de individuos (Arendt 2006, 155). En efecto, según Arendt, la violencia es incompatible con el poder, y se define a la hora de la verdad por su impotencia. Un modelo como el de Hobbes podría suprimir la política, pero jamás fundar o instaurar una nueva. Entre otras cosas, por no dejar espacio a la pluralidad.

Esta incompatibilidad del pensamiento hobbesiano (y su idea de poder) con la pluralidad y con la concepción arendtiana de política se plasma por ejemplo en el De Cive. Allí arguye que por el hecho de ser irreductiblemente plural y no singular, por ser el modo de ser de los muchos, de lo que no está unificado, la multitudo es incapaz de pactar o de prometer y, por tanto, incapaz de poseer un auténtico poder soberano (Hobbes 1999, 55 y 108). La multitud, como ha apuntado Paolo Virno (1993, 23), aparece por consiguiente como un concepto negativo y heterogéneo que debe ser exorcizado o, al menos, domesticado, transformándola en su contrario, en un populus que se presenta como una entidad homogénea con una voluntad común; en suma, como un colectivo que, por sus características, anticipa y hace posible la existencia de un Estado firmemente vertebrado sobre la unidad como el preconizado por Hobbes. ${ }^{10}$

10 Por ello no extraña que Hobbes tuviera mucho cuidado en no emplear nunca términos centrales en la teoría política escolástica como community o communitas (Tuck 1993, 311). 
En Hobbes, en definitiva, se consuma una radical privatización del poder (y de la libertad), lo que deriva en la categórica negación de la esfera pública y de la pluralidad. En este proceso, el interés juega asimismo un rol primordial, ya que el mismo Leviatán se legitima en tanto que es el monumento al interés personal de todos sus integrantes. Sin embargo, ya no se entiende el interés como el inter esse que reivindica Arendt desde la etimología, como un espacio intermedio (o entre) sin los que no puede existir lo político ni se puede desenvolver la libertad, sino como un interés desacomplejadamente privado y egoísta. El interés ya no es lo que une sino más bien lo que aleja a unos de otros o incluso los enfrenta; de donde germina un proyecto político que, en vez de unificar, separa a sus integrantes; esto hace necesaria la intervención de un poder soberano que debe servirse del miedo como instrumento político para garantizar el mantenimiento del orden.

Como ha señalado Roberto Esposito $(2003,57)$, en Hobbes el miedo ya no tiene solamente una faceta destructiva sino también constructiva e incluso fundacional. Para Arendt, en cambio, el miedo es por definición un principio antipolítico desde el cual no se puede fundar nada (Arendt 2008, 104). Al ser el miedo el fundamento de la política en Hobbes, ésta queda atada a lo privado (Arendt 1965) y entra en contradicción con su sentido más íntimo y original.

\section{Conclusión}

Hobbes comparece en el pensamiento de Hannah Arendt como un pensador mayúsculo pero indudablemente negativo, muy dañino $\mathrm{y}$ contra el cuál habría que pensar. Muchos de los problemas del presente que vivimos, como el vaciamiento de la política y la eclosión de lo social, formarían parte de su legado. Sin embargo, para ser justos, habría que entender su influencia en conexión a su contexto histórico, al nacimiento de la Modernidad. Junto a Galileo y Descartes, Hobbes habría coadyuvado a lo que la pensadora alemana denominó la alienación del mundo: ese proceso por el cual el sujeto consumó un viraje hacia su interioridad al mismo tiempo que perdía el contacto y desvalorizaba la realidad exterior, lo que para ella era la marca de contraste de la Época Moderna (Arendt 
1993, 283). Además, eso habría coincidido con el advenimiento de la Revolución Industrial, la cual propició la aparición de una avalancha de gigantescos desarrollos técnicos y donde "alcanzó la experiencia de la fabricación una predominancia tan insuperable que las incertidumbres de la acción pudieron ser olvidadas por completo" (Arendt 2008, 94-95).

Si bien es cierto que la filosofía política de Hannah Arendt tiene a Platón como su principal rival filosófico (ante todo por su posición cronológica y el enorme influjo que, en consecuencia, ejerció sobre la historia del pensamiento), Hobbes aparece a su lado como otro de esos grandes autores que desarrollaron una filosofía política incompatible con lo que para la pensadora alemana era el auténtico rostro de la política. En cierto modo, el gesto filosófico de Arendt debe ser interpretado como una tentativa de deshacer algunos de los giros realizados por Hobbes; de leer a éste por la impronta que todavía tiene en el día de hoy y leerlo bien, como si nadie lo hubiera leído antes, con el fin de regenerar la política del presente y la comprensión que de ésta se tiene. ${ }^{11}$ En su pensamiento se plasma, a la par que se enquista, el conflicto entre filosofía y política: un conflicto que anticipa muchos de los problemas y dramas de la modernidad, y que aún influye poderosamente en nuestra actualidad.

\section{Bibliografía}

Abensour, Miguel. Hannah Arendt contre la philosophie politique? París: Sens \& Tonka, 2006.

Arendt, Hannah. Sobre la revolución. Madrid: Alianza, 1988.

Arendt, Hannah. La condición humana. Barcelona: Paidós, 1993.

Arendt, Hannah. Was ist politik?: fragmente aus dem Nachlass. München: Piper, $1993 b$.

11 Uno de los puntos principales que no han sido mencionados a lo largo del artículo, y que merece una extensión que no tiene cabida aquí, tiene que ver con el pujante rol que adquiere la vida, o la preservación de ésta, en la concepción y en el objetivo de la política hobbesiana y que, en La condición humana, Arendt había relacionado fundamentalmente con la figura de la labor y por lo tanto con la crisis de la sociedad contemporánea. 
Arendt, Hannah. Entre pasado y futuro. Barcelona: Península, 1996.

Arendt, Hannah. Filosofía y política; Heidegger y el existencialismo. Bilbao: Besatari, 1997.

Arendt, Hannah. ¿Qué es la política? Barcelona: Paidós, 1997b.

Arendt, Hannah. Hombres en tiempos de oscuridad. Barcelona: Gedisa, 2001.

Arendt, Hannah. La vida del espíritu. Barcelona: Paidós, 2002.

Arendt, Hannah. Conferencias sobre la filosofía política de Kant. Barcelona: Paidós, 2003.

Arendt, Hannah. La tradición oculta. Barcelona: Paidós, 2004.

Arendt, Hannah. Sobre la violencia. Madrid: Alianza, 2005.

Arendt, Hannah. Diario filosófico: 1950-1973. Barcelona: Herder, 2006.

Arendt, Hannah. La promesa de la política. Barcelona: Paidós, 2008.

Arendt, Hannah. Los orígenes del totalitarismo. Madrid: Prisa Innova, 2009.

Birulés, Fina. Una herencia sin testamento: Hannah Arendt. Barcelona: Herder, 2007.

Bobbio, Norberto. Thomas Hobbes. Barcelona: Paradigma, 1991.

Bodin, Jean. Los seis libros de la república. Madrid: Tecnos, 1997.

Brunkhorst, Hauke. El legado filosófico de Hannah Arendt. Biblioteca Nueva. Madrid, 2006.

Canovan, Margaret. Hannah Arendt: a reinterpretation of her political thought. Cambridge: Cambridge University Press, 1992.

Collin, Françoise. L'homme est-il devenu superflu: Hannah Arendt. Paris: Jacob, 1999.

Domingo, Rafael. Auctoritas. Barcelona: Ariel, 1999.

Esposito, Roberto. Communitas: origen y destino de la comunidad. Buenos Aires: Amorrortu, 2003.

Forti, Simona. Vida del espíritu y tiempo de la polis: Hannah Arendt entre filosofía y política. Madrid: Cátedra, 2001.

Fuentes, Claudia. "La política en la hora del lobo del hombre: propuesta 
para una lectura arendtiana de la teoría del contrato social de Hobbes". Alpha 28 (2009): 245-256.

Grossi, Paolo. Mitología jurídica de la modernidad. Madrid: Trotta, 2003. Hobbes, Thomas. Leviatán, o, la materia, forma y poder de una república, eclesiástica y civil. México DF: Fondo de Cultura Económica, 1980.

Hobbes, Thomas. Diálogos entre un filósofo y un jurista y escritos autobiográficos. Madrid: Tecnos, 1992.

Hobbes, Thomas. Tratado sobre el ciudadano. Madrid: Trotta, 1999.

Hobbes, Thomas. Tratado sobre el cuerpo. Madrid: Trotta, 2000.

Hobbes, Thomas. Behemoth. Madrid: Tecnos, 2013.

MacPherson, C.B. La teoría política del individualismo posesivo: de Hobbes a Locke. Madrid: Trotta, 2005.

Pateman, Carole. El contrato sexual. Barcelona: Anthropos, 1995.

Platón. Diálogos IV: La república. Madrid: Gredos, 1986.

Platón. Diálogos VIII: Leyes. Madrid: Gredos, 1987.

Pocock, J.G.A. El momento maquiavélico: el pensamiento político florentino y la tradición republicana atlántica. Madrid: Tecnos, 2002.

Preterossi, Geminello. Autoridad: léxico de política. Buenos Aires: Nueva Visión, 2003.

Roviello, Anne-Marie. Sens commun et modernité chez Hannah Arendt. Bruxelles. Éditions Ousia, 1987.

Schmitt, Carl. El Leviathan en la teoría del estado de Tomás Hobbes. Buenos Aires: Stuhart \& Cía, 1990.

Skinner, Quentin. Liberty before Liberalism. Cambridge: Cambridge University Press, 1998.

Skinner, Quentin. Hobbes y la libertad republicana. Buenos Aires: Prometeo Libros, 2010.

Strauss, Leo. ¿Qué es filosofía política? Madrid: Guadarrama, 1970.

Strauss, Leo. Derecho natural e historia. Barcelona: Círculo de Lectores, 2000.

Tassin, Étienne. Un monde commun: pour une cosmo-politique des conflits. Paris: Seuil, 2003. 
Tönnies, Ferdinand. Vida y doctrina de Tomás Hobbes. Madrid: Revista de Occidente, 1932.

Tuck, Richard. Philosophy and Government 1572-1651. Cambridge: Cambridge University Press, 1993.

Virno, Paolo. Gramática de la multitud: para un análisis de las formas de vida contemporáneas. Madrid: Traficantes de sueños, 1993.

Zarka, Yves-Charles. Hobbes y el pensamiento político moderna. Barcelona: Herder, 1997.

Zarka, Yves-Charles. Filosofía y politica en la Edad Moderna. Madrid: Escolar y Mayo, 2008. 